\title{
The Effects of Background Color of Safety Symbols on Perception of the Symbols
}

\author{
Calvin K. L. Or ${ }^{1}$, Alan H. S. Chan ${ }^{2}$ \\ ${ }^{1}$ Department of Industrial and M anufacturing Systems Engineering \\ The U niversity of Hong K ong \\ Pokfulam, Hong Kong \\ ${ }^{2} D$ epartment of $M$ anufacturing Engineering and Engineering $M$ anagement \\ The City University of H ong K ong \\ Kowloon Tong, Hong K ong
}

\begin{abstract}
This present study investigated the effects of the background color of safety symbols on the way people perceive hazard and risk and consequent compliance to the symbols. Thirty-one Hong Kong Chinese rated perceived hazardousness, perceived severity of injury, immediacy of consequences, and likelihood of compliance for 21 safety symbols with various background colors and symbol types. A color was not tested if it was the same as the color of the symbol. This study showed that background color significantly influenced perception of the symbols. For hazard warning symbols (black background was not tested) and mandatory action symbols (blue background was not tested), red produced the highest levels of perceived hazard, injury severity, consequence immediacy, and compliance. For prohibition types of symbols (red background was not tested),
\end{abstract}


hazard, severity, consequence immediacy, and compliance levels were perceived to be higher for black than for other background colors.

Keywords: Safety Symbol, Background Color, Hazard and Risk Perception, Behavioral Compliance

\section{INTRODUCTION}

Effective safety symbols should communicate critical safety information about a product or environment so as to improve the perceptions, decision-making, and safety behavior of the users of the symbols, and thereby prevent or reduce safety problems and accidents (Wogalter \& Laughery, 2006). The literature shows that many design variables can affect how safety symbols convey information and how they impact on individual perceptions of safety. Color is one of the many obvious variables that has a large role in determining how people perceive hazards and risks, the attention that they pay to a safety symbol, and their consequent behavioral intention (Chan \& Courtney, 2001; Braun \& Silver, 1995; Leonard, 1999; W ogalter \& Laughery, 2006). For example, Chan and Courtney (2001) examined the associations between various colors and the concepts conveyed by sixteen words, including those commonly used in warning signs, such as danger, caution and stop. In their study, strong color associations were found, such as the widespread association of red with danger and green with safety. Braun and Silver (1995) assessed the effect of color and signal words on hazard perceptions and compliance with warnings. Their study found that color was a significant main effect and that red resulted in the highest level of perceived hazard and behavioral compliance. In a similar study, Leonard (1999) paired various signal words with different background colors (red and green) to test their effects on risk perception. His study indicated that background color produced significant differences in perception.

While many previous studies have focused on the examination of the connoted hazard of signal words and colors and the impact of their interaction on perceptions, the purpose of the present study was to investigate the influence of various background colors for safety symbols on perceived hazard and risk and selfreported compliance to the symbols. This study consisted of two experiments which assessed safety perceptions for three types of safety symbols and eight different background colors. Experiment 1 was used to test individual comprehension of a set of safety symbols for each of the three symbol types in order to determine those with the highest comprehension rates (the most understood ones) for subsequent use in experiment 2. Experiment 2 was designed to investigate the effects of the background color of safety symbols on perceptions of various attributes of the symbols. 


\section{METHOD}

\section{Participants}

For experiment 1, twenty-four Hong Kong Chinese participants (8 female and 16 male) from a local university were recruited. Their ages ranged from 16 to 25 years. For experiment 2, another group of participants were recruited; there were thirtyone Hong K ong Chinese (13 female and 18 male) whose ages ranged from 16 to 25 years. All participants selected for experiment 2 were tested and had normal color vision.

\section{Design and procedure}

In experiment 1, a set of 15 achromatic symbols (printed size: $20 \times 20 \mathrm{~mm}$ each) of three types was presented to participants in a questionnaire to test comprehension of the symbols. The types of symbols used were: hazard warning (5 symbols), mandatory action (5 symbols), and prohibition ( 5 symbols). The participants were asked to write down the meaning of each of the 15 symbols in a blank space next to each symbol in the questionnaire. They were told to leave the space blank when they were unable to understand the symbol. Comprehension accuracy was then analyzed. For each symbol type, the one with the highest comprehension rate was selected to be used in experiment 2 to test the effects of background color on perception. Demographic data was collected at the end of experiment 1.

Prior to the beginning of experiment 2, participants were given the PseudoIsochromatic plate test for red green color deficiency. Participants who failed the test were excluded from the experiment. Based on the results of the comprehension evaluation in experiment 1 , a symbol of each type was chosen for experiment 2 . As shown in Figure 1, the symbols chosen were: the hazard warning symbol "risk of toxicity", the mandatory action symbol "head protection must be worn", and the prohibition symbol "mobile phones prohibited".

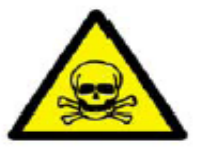

(a)

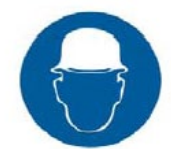

(b)

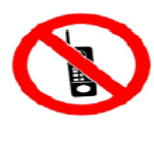

(c)

Figure 1. The three safety symbol types tested in experiment 2: (a) hazard warning, (b) mandatory action, and (c) prohibition.

These three symbols were paired with eight different background colors thus producing a total of 21 stimuli after exclusion of the three stimuli that had the same border and background color. The hazard warning symbol was black so a black 
background was not tested. Similarly a blue background was not tested for the blue mandatory action symbol and a red background was not tested for the red prohibition symbol. The eight background colors were red, green, blue, yellow, orange, grey, white, and black. The symbols were presented on a computer screen in a random order, and remained there until the participant responded. Participants were then asked to rate on a set of 9-point Likert-type scales, ranging from 0 (lowest level) to 8 (highest level), for the following four attributes for each symbol; 1) the perceived hazardousness, 2) the perceived severity of injury, 3) the immediacy of consequences, and 4) the likelihood of compliance. At the end of experiment 2, a questionnaire was used to collect demographic data of participants.

\section{Data analysis}

For experiment 1, the comprehension accuracy of the symbols was based on the correctness of the meaning given by the participants. For experiment 2, univariate analysis of variance (ANOVA) was performed to determine the effect of background color on the four dependent measures.

\section{RESULTS}

\section{Experiment 1}

Among the five symbols of each symbol type, the one that yielded the highest comprehension rate (the one that was most understood by the participants) was identified for each type: "risk of toxicity" (hazard warning type), "head protection must be worn" (mandatory action type), and "mobile phones prohibited" (prohibition type). Twenty-three of the 24 participants (96\%) were able to correctly state the reference meaning of the "risk of toxicity" symbol. Twenty-four (100\%) participants correctly described the reference meaning of the "head protection must be worn" symbol. Twenty-three (96\%) participants were able to give the reference meaning of the "mobile phones prohibited" symbol.

\section{Experiment 2}

The combination of symbol type and background color yielded twenty-one stimuli after excluding the hazard warning symbol with black background, the mandatory action symbol with blue background, and the prohibition symbol with red background, since the border colors of the symbols were the same as their background colors. M eans and standard deviations of the four dependent measures are shown in Table 1. 
Table 1. Means and standard deviations of the four dependent measures

\begin{tabular}{|c|c|c|c|c|c|c|c|c|c|c|c|c|}
\hline & \multicolumn{3}{|c|}{$\begin{array}{l}\text { Mean perceived } \\
\text { hazardousness (SD) }\end{array}$} & \multicolumn{3}{|c|}{$\begin{array}{l}\text { Mean perceived severity } \\
\text { of injury (SD) }\end{array}$} & \multicolumn{3}{|c|}{$\begin{array}{l}\text { Mean immediacy of } \\
\text { cons equences (SD) }\end{array}$} & \multicolumn{3}{|c|}{$\begin{array}{l}\text { Mean likelihood of } \\
\text { compliance (SD) }\end{array}$} \\
\hline & HW & MA & $P$ & HW & MA & $\mathrm{P}$ & $\mathrm{HW}$ & $\mathrm{MA}$ & $P$ & $\mathrm{HW}$ & $\mathrm{MA}$ & $P$ \\
\hline Red & $\begin{array}{l}6.87 \\
(1.34)\end{array}$ & $\begin{array}{l}4.81 \\
(1.60)\end{array}$ & NA & $\begin{array}{l}6.77 \\
(1.41)\end{array}$ & $\begin{array}{l}4.48 \\
(1.83)\end{array}$ & NA & $\begin{array}{l}6.84 \\
(1.49)\end{array}$ & $\begin{array}{l}5.03 \\
(2.35)\end{array}$ & NA & $\begin{array}{l}6.84 \\
(1.49)\end{array}$ & $\begin{array}{l}4.77 \\
(1.94)\end{array}$ & $\mathrm{NA}$ \\
\hline Green & $\begin{array}{l}5.26 \\
(1.57)\end{array}$ & $\begin{array}{l}3.39 \\
(1.63)\end{array}$ & $\begin{array}{l}2.16 \\
(1.61)\end{array}$ & $\begin{array}{l}5.23 \\
(1.69)\end{array}$ & $\begin{array}{l}3.19 \\
(1.54)\end{array}$ & $\begin{array}{l}2.29 \\
(1.94)\end{array}$ & $\begin{array}{l}5.35 \\
(1.89)\end{array}$ & $\begin{array}{l}3.77 \\
(2.19)\end{array}$ & $\begin{array}{l}2.29 \\
(2.09)\end{array}$ & $\begin{array}{l}5.55 \\
(1.63)\end{array}$ & $\begin{array}{l}3.65 \\
(1.76)\end{array}$ & $\begin{array}{l}3.10 \\
(1.58)\end{array}$ \\
\hline Grey & $\begin{array}{l}5.52 \\
(1.48)\end{array}$ & $\begin{array}{l}3.48 \\
(1.39)\end{array}$ & $\begin{array}{l}2.81 \\
(2.21)\end{array}$ & $\begin{array}{l}5.52 \\
(1.36)\end{array}$ & $\begin{array}{l}3.81 \\
(1.45)\end{array}$ & $\begin{array}{l}2.97 \\
(2.07)\end{array}$ & $\begin{array}{l}5.68 \\
(1.85)\end{array}$ & $\begin{array}{l}4.23 \\
(1.89)\end{array}$ & $\begin{array}{l}3.19 \\
(2.17)\end{array}$ & $\begin{array}{l}5.84 \\
(1.53)\end{array}$ & $\begin{array}{l}3.97 \\
(1.74)\end{array}$ & $\begin{array}{l}4.26 \\
(1.83)\end{array}$ \\
\hline Orange & $\begin{array}{l}5.32 \\
(1.58)\end{array}$ & $\begin{array}{l}4.00 \\
(1.65)\end{array}$ & $\begin{array}{l}2.29 \\
(1.64)\end{array}$ & $\begin{array}{l}5.45 \\
(1.52)\end{array}$ & $\begin{array}{l}4.00 \\
(1.65)\end{array}$ & $\begin{array}{l}2.42 \\
(1.57)\end{array}$ & $\begin{array}{l}5.61 \\
(1.82)\end{array}$ & $\begin{array}{l}4.52 \\
(1.90)\end{array}$ & $\begin{array}{l}3.10 \\
(2.14)\end{array}$ & $\begin{array}{l}5.58 \\
(1.54)\end{array}$ & $\begin{array}{l}4.10 \\
(1.58)\end{array}$ & $\begin{array}{l}3.71 \\
(1.81)\end{array}$ \\
\hline Blue & $\begin{array}{l}5.13 \\
(1.73)\end{array}$ & NA & $\begin{array}{l}2.23 \\
(1.96)\end{array}$ & $\begin{array}{l}4.97 \\
(1.76)\end{array}$ & NA & $\begin{array}{l}2.26 \\
(1.77)\end{array}$ & $\begin{array}{l}5.19 \\
(1.94)\end{array}$ & NA & $\begin{array}{l}3.00 \\
(2.37)\end{array}$ & $\begin{array}{l}5.13 \\
(1.69)\end{array}$ & NA & $\begin{array}{l}3.65 \\
(1.84)\end{array}$ \\
\hline Yellow & $\begin{array}{l}6.06 \\
(1.34)\end{array}$ & $\begin{array}{l}3.84 \\
(1.27)\end{array}$ & $\begin{array}{l}3.13 \\
(1.63)\end{array}$ & $\begin{array}{l}6.13 \\
(1.28)\end{array}$ & $\begin{array}{l}3.87 \\
(1.50)\end{array}$ & $\begin{array}{l}3.06 \\
(1.81)\end{array}$ & $\begin{array}{l}6.23 \\
(1.73)\end{array}$ & $\begin{array}{l}4.55 \\
(1.91)\end{array}$ & $\begin{array}{l}3.52 \\
(2.17)\end{array}$ & $\begin{array}{l}6.06 \\
(1.48)\end{array}$ & $\begin{array}{l}4.13 \\
(1.59)\end{array}$ & $\begin{array}{l}4.06 \\
(1.41)\end{array}$ \\
\hline W hite & $\begin{array}{l}5.65 \\
(1.50)\end{array}$ & $\begin{array}{l}3.26 \\
(1.61)\end{array}$ & $\begin{array}{l}2.35 \\
(1.64)\end{array}$ & $\begin{array}{l}5.68 \\
(1.38)\end{array}$ & $\begin{array}{l}3.23 \\
(1.38)\end{array}$ & $\begin{array}{l}2.39 \\
(1.76)\end{array}$ & $\begin{array}{l}5.65 \\
(1.94)\end{array}$ & $\begin{array}{l}3.68 \\
(2.18)\end{array}$ & $\begin{array}{l}2.65 \\
(2.29)\end{array}$ & $\begin{array}{l}5.71 \\
(1.55)\end{array}$ & $\begin{array}{l}3.58 \\
(1.93)\end{array}$ & $\begin{array}{l}3.58 \\
(2.06)\end{array}$ \\
\hline Black & NA & $\begin{array}{l}4.19 \\
(1.91)\end{array}$ & $\begin{array}{l}3.32 \\
(2.27)\end{array}$ & NA & $\begin{array}{l}4.26 \\
(2.13)\end{array}$ & $\begin{array}{l}3.29 \\
(2.21)\end{array}$ & NA & $\begin{array}{l}5.00 \\
(2.39)\end{array}$ & $\begin{array}{l}3.90 \\
(2.48)\end{array}$ & NA & $\begin{array}{l}4.39 \\
(1.98)\end{array}$ & $\begin{array}{l}5.16 \\
(1.73)\end{array}$ \\
\hline
\end{tabular}

$\mathrm{HW}=$ hazard warning symbol; $\mathrm{MA}=$ mandatory action symbol; $\mathrm{P}=$ prohibition symbol 
Perceived hazardousness. The ANOVA showed that there was a significant main effect of color for all three symbol types: hazard warning, $F(6,180)=10.93$, $p<0.001$; mandatory action, $F(6,180)=6.56, p<0.001$; and prohibition, $F(6$, $180)=4.96, p<0.001$. The hazard warning and mandatory action symbols with red backgrounds were perceived as most hazardous. The prohibition symbol with black background was rated as highest in hazard.

Perceived severity of injury. There was a significant main effect of color for all symbol types: hazard warning, $F(6,180)=11.32, p<0.001$; mandatory action, $F(6$, $180)=7.24, p<0.001$; and prohibition, $F(6,180)=3.82, p<0.005$. Hazard warning and mandatory action symbols with red backgrounds and prohibition symbol with black background resulted in highest ratings of injury severity.

Immediacy of consequences. The effect of background color on perceived immediacy of consequences was significant for all symbol types: hazard warning, $F(6,180)=9.57, p<0.001$; mandatory action, $F(6,180)=4.55, p<0.001$; and prohibition, $F(6,180)=5.28, p<0.001$. The hazard warning and mandatory action symbols with red background and the prohibition symbol with black background yielded highest perceived immediacy scores.

Likelihood of compliance. There was a significant main effect of color for all symbol types: hazard warning, $F(6,180)=8.39, p<0.001$; mandatory action, $F(6$, $180)=3.33, p<0.005$; and prohibition, $F(6,180)=8.14, p<0.001$. Ratings of compliance likelihood were highest for hazard warning and mandatory action symbols with red background. For prohibition type, the symbol with black background yielded a highest compliance likelihood rating.

\section{DISCUSSION AND CONCLUSIONS}

This study tested perceptions of safety symbols for three types of symbols paired with various background colors. A fter excluding the three stimuli that had the same border and background color (i.e., the hazard warning symbol with black background, the mandatory action symbol with blue background, and the prohibition symbol with red background), 21 stimuli were tested. The study revealed that the background color of a safety symbol influenced perceptions of hazard, injury severity, immediacy of consequences, and likelihood of compliance with the warnings. For the hazard warning and mandatory action symbols, of those colors tested, it was found that a red background produced the highest levels of perceived hazard, injury severity, consequence immediacy, and behavioral compliance. This finding is consistent with some safety sign color coding standards and with previous research showing that red was perceived as having a significantly higher hazard connotation than other colors (Chan \& N g, 2009; Rodriguez, 1991; Wogalter \& Laughery, 2006; W ogalter et al., 1995). Here, for the hazard warning symbol, yellow produced the second highest level of perceived hazard, injury 
severity, consequence immediacy, and compliance. However, for the mandatory action symbol type, the black background received the second highest mean ratings for the four dependent measures. For the prohibition symbol type, where a red background was not tested because the symbol was red, black conveyed a greater level of hazard, severity of injury, immediacy of consequences, and likelihood of compliance than all other background colors.

Although the use of color in safety symbols can be problematic for certain users, such as those with color deficiency, colored symbols are of great value in attracting attention more effectively than achromatic symbols (Wogalter and Laughery, 2006). Furthermore, previous studies have shown that color influenced perception of hazard as well as behavioral compliance with the symbols (Braun and Silver, 1995; Braun, Sansing, and Silver, 1994; Leonard, 1999). In the present study, the findings demonstrate that different background colors for safety symbols connoted different levels of perceived hazard, risk, and behavioral compliance. While color is one of the main design components of a safety symbol, obviously, color on its own cannot convey important safety information. Color can be used as an additional form of information dissemination, especially for gaining attention, in environments and on products where safety is an issue.

\section{ACKNOWLEDGMENT}

The work described in this paper was fully supported by a grant from the Research Grants Council of the Hong Kong Special Administrative Region, China [CityU 110508].

\section{REFERENCES}

Braun, C.C., Sansing, L., \& Silver, N.C. (1994). The interaction of signal word and color on warning labels: differences in perceived hazard. Proceedings of the Human Factors and E rgonomics Society 38th Annual M eeting, 831-835.

Braun, C.C., \& Silver, N.C. (1995). Interaction of signal word and colour on warning labels: differences in perceived hazard and behavioural compliance. Ergonomics, 38(11), 2207-2220.

Chan, A.H.S., \& Courtney, A.J. (2001). Color associations for Hong Kong Chinese. International J ournal of Industrial Ergonomics, 28(3-4), 165-170.

Chan, A.H.S., \& Ng, A.W.Y . (2009). Perceptions of implied hazard for visual and auditory al erting signals. Safety Science, 47(3), 346-352.

Leonard, D.S. (1999). Does color of warnings affect risk perception? International J ournal of Industrial Ergonomics, 23(5), 499-504.

Rodriguez, M.A. (1991). What makes a warning label salient? Proceedings of the Human Factors and Ergonomics Society 35th A nnual M eeting, 1029-1033. 
Wogalter, M.S., \& Laughery, K.R. (2006). Warnings and hazard communications. In G. Salvendy (Ed.), Handbook of Human Factors and Ergonomics (3rd ed., pp. 889-911). New Y ork: J ohn Wiley \& Sons.

Wogalter, M.S., Magurno, A.B., Carter, A.W., Swindell, J.A., Vigilante, W.J ., \& Daurity, J.G. (1995). Hazard associations of warning header components. Proceedings of the Human Factors and Ergonomics Society 39th A nnual M eeting, 979-983. 